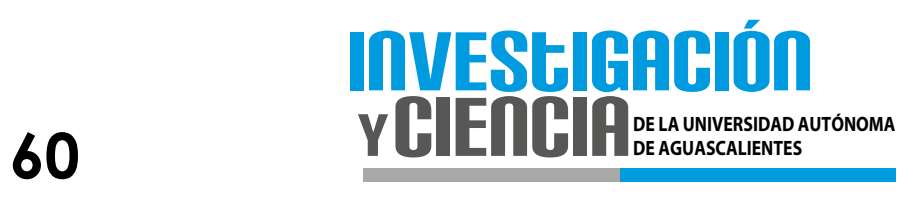

\title{
La libertad de enseñanza: un principio educativo innovador de la Constitución mexicana de 1857
}

\author{
Liberty in education: an innovative principle \\ of 1857 mexican Constitution
}

\begin{abstract}
$\searrow$ José Bonifacio Barba Casillas ${ }^{1 *}$
Barba Casillas, J. B. La libertad de enseñanza: un principio educativo innovador de la Constitución mexicana de 1857. Investigación y Ciencia de la Universidad Autónoma de Aguascalientes. Número 68: 60-69, mayo-agosto 2016.
\end{abstract}

\section{RESUMEN}

La definición del liberalismo mexicano en los años que siguieron a la independencia tuvo una fase trascendente en la revolución de la Reforma, que creó la Constitución de 1857. Este trabajo tiene el propósito de identificar los valores del proyecto educativo de esta Constitución, analizándolos en el contexto del avance de las libertades fundamentales, la educación entre ellas. Se estudian los antecedentes y características de la Constitución de 1857 para identificar sus aspectos innovadores. Los resultados muestran los rasgos de la Constitución y su sentido valoral para la educación, tanto por los principios constitucionales en conjunto como por la libertad de enseñanza en específico. Se concluye que la Constitución establece valores innovadores para la formación de la nación mexicana al reconocer un amplio conjunto de derechos del hombre y por establecer la libertad de enseñanza, una base legal y filosófica para una educación orientada a la formación moral de los ciudadanos.

Palabras clave: constitucionalismo mexicano, Constitución de 1857, libertad de enseñanza, principios educativos, valores jurídicos de la educación, Derechos Humanos.

Keywords: mexican constitutionalism, Constitution of 1857, liberty in education, educational principles, legal values of education, Human Rights.

Recibido: 5 de diciembre de 2014, aceptado: 14 de agosto de 2015

Departamento de Educación, Centro de Ciencias Sociales y Humanidades, Universidad Autónoma de Aguascalientes.

* Autor para correspondencia: jbbarba@correo.vaa.mx
ABSTRACT

The progress in the comprehension of the Mexican liberalism in the post independence years had an important phase in the Reforma revolution that produced the Constitution of 1857. This paper aims to identify the values of the educational project in this Constitution through their analysis within the context of the advance of the fundamental freedoms, the education among them. Attention is given to precedents and characteristics of the Constitution in order to identify its innovative aspects. Results show the constitutional features and their significance for education due to the constitutional principles as a whole and, specifically, by the liberty of education. It is concluded that the Constitution establishes a set of innovative principles for the construction of the Mexican nation by acknowledging a large group of human rights and setting-up a legal and philosophical base for an education focused on the moral education of the citizens by establishing the liberty of teaching.

\section{INTRODUCCIÓN}

La sociedad mexicana tiene una importante historia constitucional con dos rasgos en relación paradójica: primero, un progreso jurídico en su vida independiente con apertura al constitucionalismo occidental, de acuerdo a las circunstancias del país y a los proyectos de sociedad que se planteaban; segundo, una dificultad práctica, tanto gubernamental como social, para vivir conforme al orden constitucional. A ese entorno pertenece la cuestión de la formación ciudadana como un fin político y social por alcanzar, a la vez que como medio de transformación social. 
Las constituciones políticas en el derecho moderno contienen un proyecto de sociedad que se juridifica al determinar un conjunto de principios y valores cuya fuente y criterio organizador reside en el reconocimiento y protección de los derechos humanos, por cuya exigencia vital, filosófica y política la nación ejerce su soberanía, define una nueva forma de gobierno y las facultades y obligaciones de los gobernantes y los ciudadanos (Soberanes Fernández, 2012). En esta filosofía política del Estado democrático de derechos se precisan nuevas relaciones entre el individuo y la sociedad, originando un proyecto específico de formación ciudadana que por su fundamento en la dignidad de los individuos, en el respeto debido a sus derechos y la consecuente exigencia de una convivencia democrática en la comunidad política, representa y demanda una pedagogía orientada al desarrollo moral de los nuevos sujetos jurídicos, los ciudadanos.

México se formó como nación independiente bajo la influencia de esta filosofía política y los progresos en su constitucionalismo tienen al menos cinco fuentes: una, el desarrollo occidental de la doctrina constitucional (Galeana, 2010); dos, el desarrollo de dos tradiciones de los Derechos Humanos, a saber, la de la llustración, caracterizada sobre todo por el principio del contrato social y la tradición iberoamericana que se remonta al siglo XVI y afirma la dignidad y derechos originales de las personas y de los pueblos negados por la conquista (De la Torre, 2014); tres, la demanda de justicia de varios sectores de la sociedad, que fue precisando y ampliando el reconocimiento de los derechos y su alcance; cuatro, la demanda del debido cumplimiento del régimen constitucional en paulatina construcción, a fin de transformar las relaciones sociales y el ejercicio del poder público y privado y, cinco, su experiencia real de gobierno constitucional y las dificultades inherentes de lograr el ejercicio de la soberanía en la vida interior de la nación y ante los intereses del exterior.

En ese escenario de elaboración y vida constitucional, desde la Constitución de Apatzingán hasta la reforma constitucional de Derechos Humanos de 2011, la formación del ciudadano ha sido una cuestión jurídica y de gobierno con un lugar central, junto con la necesidad consustancial de impulsar la transformación de las relaciones sociales según el mandato de realizar todos los derechos reconocidos en cada fase histórica y normativa. Tanto por los principios jurídicos como por las necesidades de la sociedad y las vicisitudes prácticas de los gobiernos, adquirió importancia gradual el deber de garantizar el derecho a la educación por su asociación con los valores de la democracia, con la autonomía moral del individuo como base para su participación con libertad y responsabilidad en la vida social y, finalmente, con el ideal jurídico-político de justicia propio del Estado moderno de derechos (Carbonell et al., 2004).

En la vida del régimen político mexicano se encuentra la paulatina construcción del derecho a la educación por ser un elemento fundamental de las transiciones sociales, políticas, económicas y jurídicas del país. Si bien el mencionado derecho se ha fortalecido con las reformas constitucionales de 1993, 2011 y 2013, su realización es aún objeto de demandas sociales, junto con otros aspectos esenciales del Estado de derecho como la seguridad de los individuos y la eficacia de la representación política.

La necesidad de garantizar el derecho a la educación en el presente (INEE, 2010, 2014) tiene sus antecedentes en las condiciones del desarrollo de México en los siglos XIX y XX. Aunque la preocupación por la educación universal se manifestó desde finales de la vida colonial -fue objeto de atención en la Constitución de Cádiz-, así como en la revolución de Independencia y aún en el Imperio Mexicano (Tena Ramírez, 2008), el proyecto educativo republicano fue establecido de forma inicial en la Constitución de 1824, sin que el derecho a la educación fuera mencionado de manera explícita en la enumeración de derechos, por ser esta Ley fundamental un pacto mínimo producto del triunfo del primer federalismo mexicano (Gantús et al., 2008; Barba, 2014).

A mediados del siglo XIX, a 34 años de la Declaración de Independencia; a pocos años de terminada la injusta guerra con los Estados Unidos de América y de la restauración del sistema federal en 1847, la vida institucional de México enfrentaba una nueva amenaza con la dictadura de Santa Anna. Sin embargo, de tal coyuntura brotó un impulso reformador decisivo para la formación de México y para el desarrollo de la educación con la ureforma triunfante») en el periodo de 1855 a 1860 (Galeana, 1986; Vázquez, 2002). Estos años forman parte del "tiempo eje de México" que va de la Revolución de Ayutla al final del imperio de Maximiliano y que se define jurídicamente por la Constitución de 1857 y las Leyes de Reforma, recibiendo incluso un cierto 


\section{InVEStIGRCIÓn Y 1 C DE LA UNIVERSIDAD AUTÓNOMA}

impulso de continuidad en algunos aspectos por la orientación liberal del gobierno de Maximiliano (Martínez Albesa, 2007; Galeana, 201 1), quien impulsó la educación con la ley del ramo promulgada en 1865.

Si los constituyentes de 1824 habían advertido de los esfuerzos que exigiría el sistema federal y de la necesidad de la instrucción y las virtudes cívicas y privadas para asegurar la independencia de México (Cumplido, 2008-2009: 130), los años que siguieron confirmaron su previsión. Los problemas políticos del país impidieron la necesaria continuidad en la construcción de un servicio de educación que diera sustento a los planes de progreso económico y promoviera las virtudes ciudadanas. La dictadura de Santa Anna entre los años 1853 y 1855 excitó los ánimos republicanos y federalistas y el Plan de Ayutla planteó la convocatoria a un congreso constituyente invocando los mismos derechos de los independentistas en 1810, pues en torno a él se integraron antiguos insurgentes y liberales de la generación de la Reforma.

Las dificultades sociales, políticas y gubernamentales para establecer un orden constitucional con vigencia permanente en las primeras décadas de vida independiente hacen pertinente indagar acerca de las condiciones en que ocurrió la génesis y la evolución del constitucionalismo mexicano, sus alcances prácticos y sus valores educativos; pero en particular se plantea aquí la pregunta sobre la aportación que hizo la Constitución de 1857 a la cuestión educacional. En consecuencia, este trabajo se ocupa de esa fase del constitucionalismo en la que se creó la constitución de la Reforma, con el objetivo de señalar la aportación que hizo al derecho a la educación e identificar los principios básicos que como valores jurídicos dieron sustento al derecho educativo. Con el objetivo de establecer una base de comprensión de la norma constitucional y de su aportación al progreso del derecho educativo, se describen algunas de las condiciones sociales y políticas que impulsaron la elaboración de la mencionada Constitución.

\section{MATERIALES Y MÉTODOS}

Se analizaron varias obras de la historiografía mexicana para comprender los antecedentes del constituyente de 1856-1857 e identificar los problemas centrales de México en las primeras décadas de vida independiente y experiencia constitucional, así como los motivos que condujeron a otro periodo revolucionario de acuerdo con el Plan de Ayutla. En segundo término, se analizó el contenido de documentos jurídicos como el Estatuto Orgánico Provisional de la República Mexicana de 1856 y el de la Constitución de 1857 para describir sus principales características innovadoras, los principios constitucionales y el significado de sus principios y valores educativos en la nueva juridicidad del país.

RESULTADOS

En los cinco apartados siguientes se expone una comprensión de la fase del constitucionalismo mexicano de la Reforma y su aportación singular con el establecimiento de un avanzado principio educativo, la libertad de enseñanza, apoyado en nuevos principios constitucionales. La base del proyecto educacional se transformó por el marco constitucional de las libertades o derechos del hombre.

\section{Los problemas de México}

Puede afirmarse que el México independiente tuvo un solo problema de carácter general, la inestabilidad, pero esta tenía varias dimensiones interrelacionadas en la vida del país: la social -desigualdad y pobreza-, la económica, la política-gubernamental, la religiosa y la jurídica. El anhelo de paz con el que culminó la revolución de Independencia no pudo consolidarse bajo ninguna de las normas que con carácter de ley fundamental tuvieron vigencia entre 1821 y 1855, lo que permitió que en ese lapso se ensayaran todas las formas de gobierno, con la característica sobresaliente de la continuidad legislativa en casi 29 años del periodo (Sordo, 1994), lo cual fue un factor favorable para la educación.

En el periodo considerado, el problema de la dimensión jurídica no consistía en la ausencia de leyes, sino en el hecho de que las disputas ideológicas y los intereses particulares motivaban a algunos sectores y grupos sociales a no respetarlas, lo cual originó un largo periodo de abusos de las autoridades, violación de derechos ciudadanos y debilidad institucional. Tanto las disputas internas como la experiencia de división y de debilidad que se vivió al enfrentar la guerra con los Estados Unidos y los años siguientes, produjeron que el Plan de Ayutla expresara en su considerando número 7 la convicción de "Que la nación no puede continuar por más tiempo sin constituirse de un modo estable y duradero..." (Villarreal y Comonfort, 1854). Ninguna forma de gobierno, desde la Regencia y el Imperio de Iturbide hasta la República central 
y la restauración de la estructura federal en 1847 , produjeron el entendimiento y la paz y las condiciones necesarias para el progreso material y moral. Además de las disputas internas, la nación hubo de enfrentar permanentes y diversas amenazas del exterior (Vázquez, 2010).

\section{Los planes de educación}

El conjunto de circunstancias y conflictos de la vida de México entre 1821 y 1857 impidió el establecimiento de planes e instituciones educativas con viabilidad y vigencia permanente. El proyecto más importante del periodo, la reforma de 18331834, no pudo sostenerse social y políticamente. Lo que sí persistió fue la convicción liberal de que la educación requería atención pública, pero los grupos conservadores rechazaban cualquier cambio que afectara sus intereses aún cuando valoraban también la importancia de la educación en su visión del país.

La Constitución de Apatzingán señaló con claridad la necesidad de la educación para todos los ciudadanos y cada Ley fundamental del país, incluida el Acta de Reformas de 1847 y el Estatuto Orgánico Provisional de la República Mexicana de 1856, se ocupó de la cuestión educativa como asunto del Estado y como bien público, sin que alguna de ellas hiciese un reconocimiento patente o incontestable del derecho a la educación dentro del breve catálogo de derechos que cada Ley establecía.

Un signo muy expresivo de la importancia reconocida a la educación es el hecho de que no obstante la inestabilidad política y las carencias económicas, diversos planes y reglamentos entre 1825 y 1855 (1825, 1833-1834, 1835, 1842, 1854, 1855) impulsaron la institucionalización de la educación, entre los que destacan la efímera Dirección General de Instrucción Pública de 1833 y la Dirección General de Instrucción Primaria de 1842, institución que fue la base de la continuidad del esfuerzo educativo hasta la República Restaurada. La primera Constitución federal delimitó las atribuciones gubernamentales de manera general, pero lo más significativo de esa fase de juridificación fue que con ello le dio un valor público a la educación al establecer la responsabilidad del Estado (Barba, 2014). De ahí en adelante, ese principio fue reiterado en todas las leyes fundamentales y fue la base para diversos esfuerzos legislativos y de políticas públicas para ordenar, impulsar y mejorar la educación haciendo siempre referencia a la formación cívica o moral.

\section{El Plan de Ayutla y la revolución de la Reforma}

El momento culmen del proceso de nacimiento de México debido a la Revolución de Ayutla y la Constitución de 1857 (Vázquez, 2002) tuvo entre sus componentes distintivos el ser un impulso para la transformación de las formulaciones que antecedieron para el proyecto educacional de México debido al hecho de establecerlo de forma distintiva entre las libertades políticas reconocidas en la nueva Ley fundamental.

El Plan de Ayutla señaló varios problemas del país -amenaza a las libertades públicas, peligro del absolutismo, mal gasto y corrupción en los bienes públicos y el amago a la independencia nacional- y programó la convocatoria a un congreso constituyente previendo que el gobierno interino atendiera al ejército para que fuera "apoyo del orden y de las garantías sociales", algo de suma urgencia para el país (Villarreal y Comonfort, 1854). Esta preocupación por la estabilidad institucional y las garantías individuales condujo a que entre el Plan de Ayutla y la Constitución de 1857 el gobierno se rigiera por el Estatuto Orgánico Provisional de la República Mexicana, proclamado por Ignacio Comonfort para ofrecer seguridad jurídica, si bien no fue aprobado por el Congreso. El Estatuto era de orientación liberal moderada y tuvo entre sus propósitos esenciales proteger los derechos y regular la acción del gobierno mientras se aprobaba la nueva Constitución (Labastida, 1967; Valadés, 2013), siendo así una muestra de autolimitación de la revolución y del Estado de derecho que impulsaba.

Es relevante también esta norma porque aun siendo provisional se ocupó de la educación: en el Artículo 38 prohibió los monopolios en la enseñanza y en el ejercicio de las profesiones; en el Artículo 39 determinó que la enseñanza privada fuese libre y que el poder público no tendría «mas intervencion (sic) que la de cuidar de que no se ataque la moralı. Decretó también normas para impulsar la educación, como la atribución de los gobernadores de «crear fondos para establecimientos de instrucción» (Artículo 117, VI) y la de "Fomentar la enseñanza pública en todos sus ramos) (X) (Comonfort, 1856). Con estos elementos, el Estatuto adquirió dos rasgos importantes: primero, da continuidad a la preocupación gubernamental y legislativa precedente de fomentar la educación afirmando así la responsabilidad del Estado; segundo, anuncia un cambio constitucional al que se orientaban los liberales de pensamiento más avanzado para establecer la libertad de enseñanza. 


\section{Características de la Constitución de 1857}

Dada la experiencia social y política de las décadas precedentes, en particular de la dictadura de Santa Anna entre 1853 y 1855, la nueva Ley fundamental pretendía darle estabilidad legal e institucional al país, unificar la nación enraizándose política y culturalmente en el anhelo de independencia de 1810-1821. Otro motivo surgió del hecho de que los monarquistas estaban activos manteniendo su interés de traer a México un príncipe europeo como gobernante.

Si bien el propósito del grupo liberal fue terminar con la dictadura de Santa Anna y crear una nueva constitución que unificara al país, el rechazo de los conservadores expresó la permanencia del conflicto entre dos proyectos de nación que generaron inestabilidad por décadas. La oposición conservadora existía desde antes del congreso constituyente, motivo por el cual los liberales enfatizaron la búsqueda de la unidad (Rabasa, 1997; Martínez Albesa, 2007). Esta fue una de las tres garantías del Plan de Iguala y se mantuvo como valor político hasta expresarse en los propósitos constitucionales básicos del Plan de Ayutla, pero no pudo evitarse la reacción militar de los conservadores. La Guerra de Reforma fue el desenlace del "choque de dos mentalidades opuestas", pero el conflicto ideológico pervivió e hizo necesario que los liberales incluyeran las Leyes de Reforma en la Constitución en 1873 (Martínez Albesa, 2007: 1287).

La Reforma y el trabajo de formular la nueva constitución fueron una experiencia que integró a la primera generación de liberales, los vinculados a la Insurgencia y la primera república federal, con la segunda generación, cuyo líder devino Benito Juárez. Esta conjunción de generaciones fue esencial para el avance jurídico-político de la Reforma, en la que tuvo un papel importante Valentín Gómez Farías, liberal radical constituyente en 1824 y en 1857 , de acción controvertida.

La Constitución de 1857, producto de una revolución que se dio a sí misma un marco legal de acción en el Estatuto mencionado arriba, tiene entre sus características sobresalientes las siguientes:

- Representa la construcción constitucional más elaborada del México independiente, producto del trabajo de los hombres más ilustrados e inteligentes de esa etapa de la sociedad mexicana.
- En estrecha relación con el propósito de conciliación, se afirmó el ejercicio de la soberanía del pueblo, pues el Congreso decretó la nueva Norma fundamental "En el nombre de Dios y con la autoridad del Pueblo Mexicano", apoyándose en la legitimidad de la Independencia (Congreso Constituyente, 1857). No obstante ser una norma conciliadora gracias al esfuerzo y congruencia de los liberales moderados (Martínez Albesa, 2007: 1238), las Leyes de Reforma le dieron mayor alcance transformador ante la resistencia de los conservadores.

- Establece una nueva institucionalidad reconociendo el más amplio catálogo de Derechos del Hombre hecho hasta entonces por un Constituyente mexicano, gracias al impulso liberal. Estos derechos son los principios que dan su nuevo valor ético a la Ley y que originan la exigencia de promover la formación moral correspondiente en los ciudadanos, tanto por la acción cotidiana del Estado como garante de los derechos en el ejercicio del gobierno, como por la vida social democrática y la institución escolar, que habrá de promover el conocimiento, aprecio y vivencia de los principios de la Ley fundamental.

- Como consecuencia del rasgo precedente, la Constitución fortalece al Estado y su autoridad social (Martínez Albesa, 2007; Bautista, 2011) al establecer que "El pueblo mexicano reconoce, que los derechos del hombre son la base y el objeto de las instituciones sociales" (Artículo 1), fijando así el principio de validez para toda ley y toda autoridad. Junto con el fortalecimiento del Estado, el constituyente previó la protección del ciudadano y el control de la acción gubernamental al establecer el juicio de amparo y el juicio político.

- En consonancia con el reconocimiento de los derechos, se decretó que "La soberanía nacional reside esencial y originariamente en el pueblo. Todo poder público dimana del pueblo y se instituye para su beneficio" (Artículo 39) y con base en ese principio ratifica la forma de gobierno: "Es voluntad del pueblo mexicano constituirse en una república representativa, democrática, federal..." (Artículo 40).

- Resolvió, aunque no en definitiva, cuestiones planteadas desde la consumación de la Independencia como la limitación al militarismo y a la influencia política de la Iglesia -el clericalismo- (Hernández, 1967: 163). 
- Eliminó la religión de Estado -es la primera Ley fundamental no confesional del Estado Mexicano- y otorgó a la autoridad federal atribuciones legales en materia de culto religioso (Artículo 123).

En suma, si bien esta Norma puso las bases de una democracia liberal centrada en derechos individuales y su aplicación tuvo diversas dificultades (De la Cueva, 1994), por ella, la experiencia conjunta de liberales radicales y moderados ayudó a "romper las trabas coloniales" del país (Labastida, 1967: 247) y "sentó las bases institucionales del actual andamiaje constitucional" (Aguirre et al., 2009: IX).

\section{Los valores educativos de la Constitución}

La Constitución de 1857 fue innovadora no sólo en lo que concierne a su principio educativo fundamental, la libertad de enseñanza, sino que lo fue en conjunto, como se expuso en los rasgos descritos arriba; aunque en varios de sus elementos dio continuidad a la Constitución de 1824, como es el caso de la opción por la forma republicana de gobierno y la estructura federal. La fuente general del carácter innovador del legislador mexicano de la Reforma es la recepción del constitucionalismo moderno de la llustración en el que la división de poderes y el reconocimiento de los derechos fundamentales son un contenido mínimo (Carbonell et al., 2004: XIII; Soberanes Fernández, 2012).

Los valores educativos, como elemento jurídico útil para la comprensión constitucional, se expresan en dos formas interrelacionadas; la primera es la Constitución misma por su naturaleza de suprema, y las normas educativas específicas, la segunda. En el conjunto axiológico de la norma nacional los valores educativos de las normas específicas están subordinados a ella, pero a su vez adquieren por tal relación mayor alcance y trascendencia, pues los derechos integran una unidad ética en tanto prerrogativas de los seres humanos.

Los Derechos Humanos, como origen estructurador de una constitución a partir de la dignidad del ser humano, son signos de valores y se expresan como principios constitucionales -por ejemplo la igualdad ante la ley-, o les dan a estos sustento y contenido en el conjunto de elementos de la norma, como es el caso del valor justicia, fin primordial del derecho. En la necesaria perspectiva política de esta axiología jurídica, puesto que la Ley fundamental es constitución política de una

\section{A NTO DE 1857 .}

Fi 5 de Febrero ne juró la Constitucion federal de los Fintados Unidos Mexieanox, por el Solverano Congrepo constituyente y por el Supremo Gobierno. Fis como sigue:

\section{MINISTERIO DE GOBEIRNACION.}

Ei Feremo. Sr. Presidente sustitute se ha kervide dirijirme el dereto que sigue:

IGNACIO cosonforT, Presidente sustitute de la Republica Mexicana,

a los habitantes de clla, sabed:

Que el Congreno estraordinario constituyente ha decretado lo que vigue:

Ein el nombre de Dios $y$ con la autoridad del Pueblo Me. xienno.

I.on representantes de los diferenten Fintados, del Distrito y Territorion que componen la Repablien de Mcxies, IIamados por el plan proelamado en Ayutia el 1." A. Narko de 1854 , refirmudo en Aenpuleo ol din 11 del mismo men y nos, y por In convoentorin expedidn el 17 de Oetubre de 1855 , para conslituir a la Xarion bajo la forma de repablien demorratiea, re. prenentativa, proular, poniendo en ejereicio los poderes con que entan inventidos, eumplen con su sito eneargo deeretando la siguiente:

Figura 1. Proemio de la promulgación de la Constitución de 1857. Imagen tomada de Cumplido (2008-2009).

sociedad, los valores se expresan, además de la manera representada por los derechos, como principios de gobierno o de organización del Estado, como es el caso de la división de poderes, que está ordenada a la protección de los derechos y a la realización de la justicia. Así, los valores se manifiestan como creencias de que una forma de vida social o un modo de estructurar las relaciones entre los individuos deben ser reconocidos como bienes públicos y protegerse. Los primordiales de ellos, los derechos fundamentales, son la base de la Ley calificada precisamente como fundamental en el constitucionalismo democrático moderno. Por lo anterior, se afirma la tesis de que los valores educativos de la Constitución se expresan en las dos formas mencionadas.

En lo que concierne a la primera forma de expresión de los valores educativos, la Constitución misma, debe considerarse que si la ciudadanía es una afirmación política del sujeto poseedor de derechos, una condición social que se deriva de la regulación de la acción y una forma de vida personal que está contenida en la Ley y se desprende de ella como proyecto, como finalidad, por la actualización de las libertades y la transformación de las relaciones sociales que ellas generan, por todo ello, entonces, los valores educativos de la Consti- 
tución de 1857 están integrados, como un acervo, por todos aquellos que sostienen los principios liberales de la Norma en cuestión, desde los que afirman que la soberanía reside originariamente en el pueblo (Artículo 39) y que este reconoce que "los derechos del hombre son la base y el objeto de las instituciones sociales" (Artículo 1), hasta cada uno de los que aplican estos principios, empezando por la afirmación de la libertad como condición existencial y política básica (Artículo 1) y siguiendo por la exposición del conjunto de las libertades -enseñanza, profesión, trabajo, expresión de las ideas, asociación, etc.-, hasta el establecimiento de los poderes divididos, sus atribuciones y responsabilidades, en suma, la sujeción a la ley. Para autoridades y para ciudadanos se constituye la convivencia como ámbito de libertades y de responsabilidad o, en otros términos, significa que el acto de reconocimiento de los derechos es la expresión de valores formativos en la comunidad política. En el caso particular de la libertad de enseñanza, con ella se reconoce a la educación como valor social, político y personal. Siendo una libertad fundamental, como valor tiene jurídicamente esa misma propiedad.

Por la afirmación que la Ley hace de la Independencia como su origen histórico y como actualización que es ella misma del sentido de aquel proyecto nacional tras los tiempos de inestabilidad, este valor político es asumido por el legislador como base histórica de la axiología constitucional expresada en el reconocimiento de los derechos del hombre, por un lado. Por el otro, dado que la Independencia afirma y ejerce el principio de la soberanía del pueblo y de este surge la forma del Estado y sus fines en relación con los individuos y la sociedad, los valores que los constituyentes reconocen como elementos para constituir la sociedad en cumplimiento del encargo que se derivó de la revolución de Ayutla, todos ellos resultan valores educativos; es decir, componentes de gran significación para la formación de la identidad ciudadana y para las relaciones entre individuos y grupos sociales. En otras palabras, el reconocimiento de los Derechos Humanos y la responsabilidad de garantizarlos establecen los valores del Estado y la fuente de su autoridad que será, entre otras expresiones, vivida como acción formadora de valores. Estos transitarán de su existencia formal en la Ley a la existencia personal y relacional en la convivencia. Por representar el contenido sustancial de la Ley y por su transición, implican el desarrollo moral del sujeto por la internalización de ellos como criterios de juicio y guía de comportamiento en el horizonte de respeto a los derechos y de justicia delineada en los principios constitucionales. En esta visión, por ejemplo, el estado de justicia al que la sociedad aspira habrá de derivarse del respeto a los derechos por parte de cada ciudadano, lo cual depende de que conozca y asuma los valores jurídicos por una pedagogía política. La búsqueda de la conciliación por los liberales moderados del constituyente de 1857 deberá alcanzarse, entre otros medios, por la tolerancia como distintivo de la comunidad política. Además, como la república se constituye democrática (Artículo 40), se deriva de ahí otro elemento que fortalece la necesidad de la educación política de los ciudadanos conforme a los valores constitucionales.

En síntesis, si por consecuencia de que los Derechos del Hombre "son la base y el objeto de las instituciones sociales" y todas las leyes y autoridades "deben respetar y sostener las garantías que otorga" la Constitución (Artículo 1), está ahí contenido el hecho jurídico y político de que la mencionada norma fundamental es un proyecto educativo y sus principios/valores son los correspondientes a tal proyecto. Surgen así de la Norma que da fines para el gobierno y la vida social, los fines de la educación y esta es establecida como institución pública, lo cual ocurre específicamente con el Artículo 3 al decretar la libertad de enseñanza. Esto conduce a la segunda forma de expresión de los valores.

La segunda expresión de los valores educativos está en las normas que se ocupan específicamente de la educación pero cuyo entendimiento cabal depende de la primera forma, como se ha expuesto arriba; es decir, que en la afirmación de las libertades está el valor educativo central de la Constitución. Se crea la unidad axiológica de las libertades en los individuos actuantes en una sociedad que las reconoce y las protege en varias de sus expresiones vitales y jurídicas. Ahí, al decretar que "La enseñanza es libre", se produce una particularización de la declaratoria general de los Derechos del Hombre como "base y objeto de las instituciones sociales". Se crea un enlace entre el Artículo 1 que contiene el valor educativo general de la Constitución y el valor particular de la libertad de enseñanza que se institucionaliza y deberá ser realizado en la vida social.

Si bien en el contexto social y político del debate sobre la enseñanza estaba la cuestión de los 
gremios y los monopolios como probable amenaza que hacía necesaria la vigilancia del gobierno, la libertad de enseñanza se propuso en el proyecto del artículo con un sentido filosófico nuevo por su amplitud social y jurídica, y los liberales puros, como José María Mata, lograron que se aprobara como muestra de congruencia con los principios que promovía su partido (Monroy, 1956; Zarco, 1987; De la Cueva, 1994). Ignacio Ramírez argumentó que estando reconocida la libertad de pensamiento y de expresión, el "derecho de enseñar" era una consecuencia inobjetable y la valoraba como expresión de la igualdad ante la ley (Ramírez, 2009). En tal sentido fue aprobado el artículo.

Esta libertad particular de la enseñanza permitió crear uno de los ámbitos públicos, o bien, una institución constitucional, que quedaba bajo la protección de garantías decretada en el Artículo 1 de la Constitución. La nueva libertad era inseparable de las otras y venía a ser condición necesaria para que los ciudadanos se formaran en los valores de la nueva juridicidad, que en realidad se condensan - integran en la naturaleza democrática de la república y sus otros rasgos de representativa y popular.

Si la Constitución fue una creación culminante del progreso social y político en el reconocimiento de las libertades -insuficiente aún frente a cuestiones sociales como la desigualdad, el trabajo, el problema agrario-, la declaratoria constitucional de la libertad de enseñanza abrió el proyecto de formación ciudadana más allá de lo que las leyes fundamentales precedentes lo habían hecho. Esta libertad, por representar la formación de los ciudadanos en una sociedad de derechos, es el símbolo más completo de la propia Constitución porque si bien esta solo dice "La enseñanza es libre", lo hace al interior de su propia naturaleza transformadora: una nueva ética política que incluye el Estado laico (Valadés, 2006). La libertad de enseñanza crea exigencias para el Estado en tanto garante de la misma; para la sociedad, en tanto comunidad democrática en formación y para los ciudadanos, porque su afirmación no es un acto formal aislado y tiene como referente primigenio la soberanía del pueblo, que exige aprender a ejercerla.

La importancia dada a la libertad de enseñanza como principio del nuevo orden normativo liberal, junto con el énfasis federalista, produjo una condición gubernamental significativa para la enseñanza: la Constitución no estableció una distribución de atribuciones entre los niveles de gobierno. Las normas aplicables de manera indirecta establecieron que las Secretarías de Estado necesarias para la administración pública federal serían fijadas por una ley del Congreso (Artículo 86), por un lado y, por el otro, al no haber facultades para el Ejecutivo federal en relación con la enseñanza, se entendería que quedaban reservadas a los Estados (Artículo 117). La acción del Ejecutivo federal quedó como asunto de la legislación secundaria, que empezó a formularse en 1861. En los estados, sería materia de sus constituciones y de su legislación.

Ante la guerra que se produjo por el rechazo de los conservadores a la Constitución, los liberales radicales decidieron avanzar en la transformación jurídica y social del país y promulgaron en los años siguientes las Leyes de Reforma. Con ellas, la libertad de enseñanza adquirió un entorno jurídico que dio mayor alcance a la nueva Norma fundamental, en especial por el principio de la separación del Estado y la Iglesia, que afirmó la soberanía del primero y la supremacía de la Constitución. La libertad de enseñanza, apoyada en la laicidad del nuevo

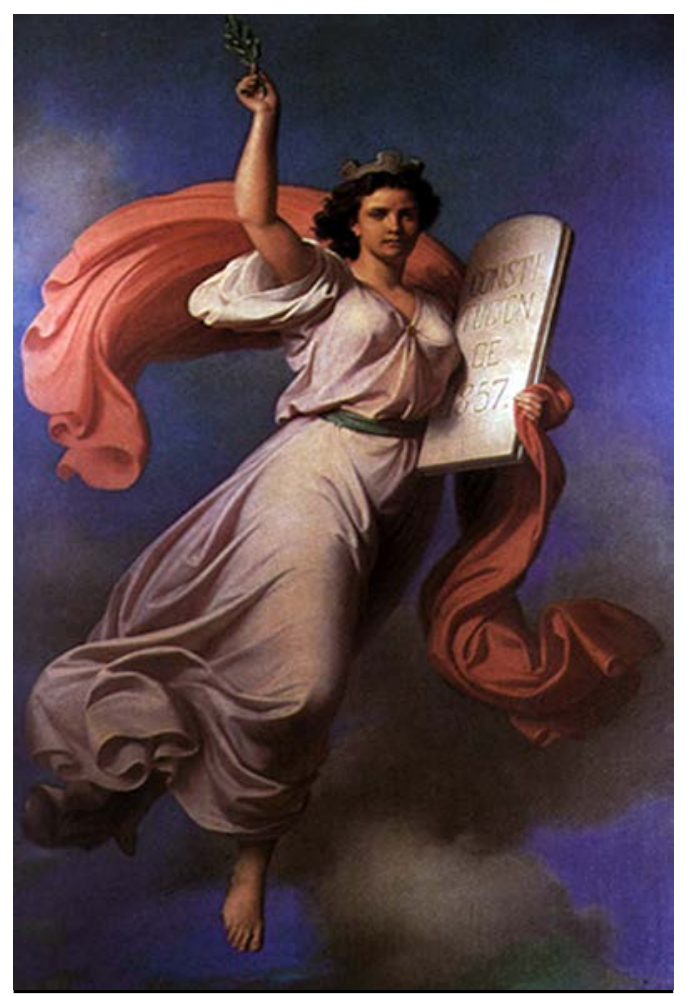

Figura 2. Petronilo Monroy, Alegoría de la Constitución de 1857 , 1868. Palacio Nacional. Imagen de Monroy (1868). 
Estado de derechos, se estableció como la base política y social que dio a la formación ciudadana una clara orientación para promover el desarrollo moral de los individuos por medio del conocimiento, vivencia y asunción personal de las libertades fundamentales. Para este fin, los valores educativos de la Constitución dependerían del buen gobierno, de la calidad democrática de la vida social y de la institución escolar que crearan las políticas públicas.

\section{CONCLUSIONES}

La inestabilidad de México en las primeras décadas de su independencia creó dialécticamente condiciones para impulsar la reforma de la sociedad y para fortalecer la institucionalidad pública con una nueva Constitución liberal que reconoció los Derechos del Hombre «como base y objeto de las instituciones socialesı. En ese rasgo distintivo de la Ley, la libertad de enseñanza dio apertura política y social a la educación, pues se estableció como libertad fundamental.
Este elevamiento de la educación como valor político en la Norma de 1857 fue acrecentado por el conjunto de los principios axiológicos que estructuraron a esta.

El impulso emancipador de la Reforma, que se expresó de manera particular por el logro liberal del establecimiento de la libertad de enseñanza, le otorgó a esta la sustancia de ser un principio jurídico que compendia la exigencia de la nueva ciudadanía de los Derechos del Hombre como cimiento de formación política y moral por la conjunción de libertades. Igual que lo plantearon los constituyentes de 1824, la Independencia de la nación continuaría descansando en las virtudes de sus ciudadanos, pero el constituyente de 1857 aportó la axiología necesaria para que la sociedad tuviera la institucionalidad democrática propia de la vivencia de las libertades y las obligaciones de gobernantes y ciudadanos.

LITERATURA CITADA

- $\quad$ AGUIRRE, S. S. et al. Presentación. En Suprema Corte de Justicia de la Nación, La Constitución de 1857. Homenaje en su CL Aniversario (IX-X). México: Suprema Corte de Justicia de la Nación, 2009.

- BARBA, J. B. La sociedad política mexicana y la formación moral del ciudadano. Apertura del proyecto en la Constitución de 1824. Revista Mexicana de Investigación Educativa, 19(62): 893-916, 2014.

- BAUTISTA, C. La cuestión religiosa en el Congreso Constituyente de 1856-1857. En Y. Padilla Rangel, L. Ramírez Hurtado \& F. Delgado Aguilar (Coords.), La historia de México a través de sus regiones: Nuevos acercamientos a la historiografía regional, siglos XIX y XX (102-123). Aguascalientes, México: Universidad Autónoma de Aguascalientes, 2011.

- CARBOnelL, M. et al. Presentación. En M. Carbonell, O. Cruz Barney \& K. Pérez Portilla (Comps.), Constituciones históricas de México (XIII-XVI). México: Porrúa, 2004.

- CUMPLIDO, I. (Ed.). Colección de Leyes fundamentales que han regido en la República Mexicana y de los planes que han tenido el mismo carácter 1821-1857. México: Miguel Ángel Porrúa, 390 pp., 1857, edición facsimilar 2008-2009.

- De La CUeVA, M. La Constitución de 5 de febrero de 1857. En A. L. Izquierdo y de la Cueva (Comp.), El humanismo jurídico de Mario de la Cueva: Antología (220-315). México: FCE/UNAM, 1994.
DE LA TORRE, J. A. Tradición iberoamericana de derechos humanos. México: Porrúa/Escuela Libre de derecho, 273 pp., 2014.

- GaleanA, P. (Comp.). el constitucionalismo mexicano. Influencias continentales y trasatlánticas. México: Senado de la República-Siglo XXI Editores, 382 pp., 2010.

- GAleanA, P. La fascinación por el imperio. México: Centro de Estudios de Historia de México Carso, 295 pp., 2011.

- GAleANA, P. La tercera reforma. En B. Bernal (Coord.), Memoria del IV Congreso de Historia del Derecho Mexicano (315-331). Tomo I. México: UNAM, 1986.

- GANTÚS, F. et al. La Constitución de 1824. La consolidación de un pacto mínimo. México: El Colegio de México, 203 pp., 2008.

- HERNÁNDEZ, O. A. La lucha del pueblo mexicano por sus derechos constitucionales. En Cámara de Diputados (Ed.), Derechos del pueblo mexicano. México a través de sus constituciones (63-30). Tomo I. México: Cámara de Diputados, 1967.

- INEe (INSTituto nacional para la eVAluación de la EDUCACIÓN). El derecho a la educación en México. Informe 2009. México: Autor, 140 pp., 2010.

- INEE (INSTItUTO NACIONAL PARA la EVALUACiÓn DE la EDUCACIÓN). El derecho a una educación de calidad. Informe 2014. México: Autor, 132 pp., 2014. 
- LABAStIDA, H. Las luchas ideológicas en el siglo XIX y la Constitución de 1857. En Cámara de Diputados (Ed.), Derechos del pueblo mexicano. México a través de sus constituciones (199-300). Tomo Il. México: Cámara de Diputados, 1967.

- MARtínez alBeSA, E. La Constitución de 1857. Catolicismo y liberalismo en México. 3 vols. México: Porrúa, 1284 pp., 2007.

- $\quad$ MONROY, G. La Instrucción Pública. En L. González, L. Cosío \& G. Monroy, Historia moderna de México. República Restaurada. Vida social (634-743). Vol. III. México: Editorial Hermes, 1956.

- RABASA, E. O. Historia de las constituciones mexicanas. México: UNAM, 105 pp., 1997

- RAMÍREZ, I. La palabra de la reforma en la república de las letras. Una antología general. Selección y estudio preliminar de Liliana Weinberg. México: FCE/Fundación para las Letras Mexicanas/UNAM, 498 pp., 2009.

- SOBERANES FERNÁNDEZ, J. L. El pensamiento constitucional en la Independencia. México: Porrúa-UNAM, 201 pp., 2012.

- SORDO, R. El congreso y la formación del Estado-nación en México, 1821-1855. En J. Vázquez (Coord.), La fundación del Estado mexicano, 182 1-1855 (135-178). México: Nueva Imagen, 1994.

- TENA RAMíREZ, F. Leyes Fundamentales de México 1808-2005. México: Porrúa, 1180 pp., 2008.

- VALADÉS, D. Las Funciones de la Constitución. En D. Valadés (Coord.), Derechos del Pueblo Mexicano. México a través de sus Constituciones (15-158). Vol. I. México: Miguel Ángel PorrúaCámara de Diputados, 2006.

\section{InVESEIGACIÓn YCIERCI

- VALADÉS, D. Reflexiones sobre el Estatuto Orgánico de 1856. En Supremo Gobierno, Estatuto Orgánico Provisional de la República Mexicana (5-20). México: Miguel Ángel Porrúa, edición facsimilar, 2013.

- VÁZQUEZ, J. Décadas de inestabilidad y amenazas. México, 1821-1848. México: El Colegio de México, 357 pp., 2010.

- VÁZQUEZ, J. (Coord.). El nacimiento de México, 1750-1856. De las reformas borbónicas a la Reforma. En J. Vázquez (Coord. gral.), Gran Historia de México. Vol. III. México: Planeta De Agostini-CONACULTA-INAH, 400 pp., 2002.

- ZARCO, F. Historia del Congreso Constituyente de 1857. México: INEHRM, 1987.

\section{De páginas electrónicas}

- COMONFORT, I. Estatuto Orgánico Provisional de la República Mexicana, 1856. Recuperado el 19 de noviembre de 2014, de http://www.ordenjuridico.gob.mx/Constitucion/1856.pdf

- CONGRESO CONSTITUYENTE. Constitución Política de la República Mexicana de 1857. México: Instituto de Investigaciones Jurídicas, 26 pp., 1857. Recuperado el 28 de agosto de 2014, de http://www.juridicas.unam.mx/infjur/leg/conshist/pdf/1857.pdf

- MONROY, P. Alegoría de la Constitución de 1857 [Pintura]. 1868. Recuperado de http://webpages.cegs.itesm.mx/servicios/hdem/ref_liberal/imagenes/constitumonroy.jpg

- VIllarreal, F. y COMONFORT, I. Plan de Ayutla. México: Cámara de Diputados, 3 pp., 1854. Recuperado el 28 de agosto de 2014, de http://www.ordenjuridico.gob.mx/Constitucion/ $\mathrm{CH} 4 . \mathrm{pdf}$ 